\section{Memory retrieval and sentence processing: Differences between native and non-native speakers}

Efficient comprehension of sentences requires rapidly and continuously accessing and integrating different sources of information in real time. Psycholinguists have developed detailed models and theories to account for the processes involved in on-line sentence comprehension as well as a number of sophisticated experimental designs for studying these processes. But how about real-time sentence processing in bilinguals? The study of bilingual sentence processing has received considerable attention and has led to a remarkable growth of experimental studies over the last 10 years. The focus of these studies has been on late bilinguals, i.e., on second-language (L2) learners who learned a non-native language after early childhood, as adolescents or adults. These studies have revealed both similarities and differences between native (L1) and non-native (L2) sentence processing. Several proposals have been made to account for the experimental findings, but the significance and nature of native vs. non-native differences in sentence processing has remained controversial. Some researchers have claimed that L1 and L2 sentence processing are essentially the same and that observed performance differences between native and non-native sentence comprehension are due to peripheral factors, e.g., decoding problems, working memory limitations, slower processing speed, difficulties with lexical access and retrieval, or a reduced ability to predict during L2 processing (e.g., McDonald, 2006; Hopp, 2016; Kaan, 2014). Others have posited more substantial differences between L1 and L2 processing. One prominent proposal is Clahsen and Felser's (2006a, b) Shallow-Structure Hypothesis ( $\mathrm{SSH})$. Assuming multistream models of language processing (e.g., Ferreira \& Patson, 2007) with two routes from form to meaning, a heuristic one that employs surface-form information, lexical and semantic cues, and an algorithmic route that relies on a full grammatical parse, the SSH holds that L2 processing relies less on grammatical and more on non-grammatical information sources, in comparison to L1 processing of syntactic (and morphological) phenomena.

Against this background, our KEYNOTE ARTICLE (Cunnings, 2017a) offers a critical review of recent research on the topic and puts forward a novel proposal of how sentence comprehension in late bilinguals differs
JUBIN ABUTALEBI

University Vita-Salute San Raffaele, Italy

HARALD CLAHSEN

Potsdam Research Institute for Multilingualism, Germany from native L1 processing. Adopting psycholinguistic models of sentence comprehension, specifically models which assume that comprehension essentially involves skilled memory retrieval (e.g., Lewis, Vasishth \& Van Dyke, 2006), Cunnings attributes non-nativelike L2 processing patterns to an increased susceptibility to retrieval interference during memory access in nonnative relative to native processing. Considering previous research findings from the point of view of memory retrieval models of processing provides a fresh and, to our minds, a very interesting perspective on the topic.

Cunnings' keynote article elicited 16 commentaries, an exceptionally large number of responses, from wellknown experts in experimental psycholinguists and/or bilingualism research. Many commentators applaud Cunnings' attempt to derive the specifics of nonnative sentence comprehension from difficulties in cuebased memory retrieval. At the same time, however, commentators are concerned that Cunnings' account may not be explicit enough (Malko, Ehrenhofer \& Phillips, 2017; Tremblay \& Coughlin, 2017; Kaan, 2017) and in some cases may go beyond what is currently supported by empirical evidence (Dillon, 2017), that core notions may be too vague and in need of clarification (Juffs, 2017; Gabriele, Fiorentino \& Covey, 2017), and that attested L1/L2 differences remain that are hard to explain in terms of interference and retrieval difficulties (Jacob, Lago \& Patterson, 2017). Experts in bilingualism raise methodological concerns and draw attention to factors neglected by Cunnings, such as the potential influence of an L2 on an individual's skills in the L1 (Dussias, BeattyMartínez \& Perrotti, 2017) and the role of individual differences (Montrul \& Tanner, 2017; Hopp, 2017; Keating, 2017). In addition, some commentators point out that Cunnings' proposal may indeed be compatible with alternative accounts of L2 grammatical processing such as the Shallow Structure Hypothesis, Sorace's Interface Hypothesis or Ullman's Declarative/Procedural Model (Hamrick \& Ullman, 2017; Kaiser, 2017) and with alternative memory-based models of sentence processing (Futrell \& Gibson, 2017; Wagers, 2017). Omaki (2017) notes that in some respects Cunnings' account even "lost some of the empirical strength and theoretical virtues of the SSH". Cunnings (2017b) uses the opportunity of 
his response for a detailed rebuttal of the points raised by the commentators. In particular, Cunnings' response includes a discussion of recent findings from L2 sentence processing studies that cannot be easily accounted for in terms of increased memory interference during L2 processing (e.g., Boxell \& Felser, 2017) and lays out specific predictions for future studies that would allow us to decide to what extent $\mathrm{L} 1 / \mathrm{L} 2$ processing differences are due to memory interference and to what extent to shallow parsing. Together with the commentaries and the author's response, this keynote article contributes to linking different fields of research (viz., psycholinguistics, memory research, and the study of bilingualism) in what we think is a very promising attempt at a deeper understanding of the differences between native and nonnative language processing.

We hope our readers will enjoy the keynote article together with the commentaries and the author's response as well as the interesting regular research articles presented in the current issue.

\section{References}

Boxell, O., \& Felser, C. (2017). Sensitivity to parasitic gaps inside subject islands in native and non-native sentence processing. Bilingualism: Language and Cognition, 20, 494-511. doi:10.1017/S1366728915000942

Clahsen, H., \& Felser, C. (2006a). How native-like is non-native language processing? Trends in Cognitive Sciences, 10, 564-570. doi:10.1016/j.tics.2006.10.002

Clahsen, H., \& Felser, C. (2006b). Grammatical processing in language learners. Applied Psycholinguistics, 27, 3-42. doi:10.1017/S0142716406060024

Cunnings, I. (2017a). Parsing and working memory in bilingual sentence processing. Bilingualism: Language and Cognition, 20. doi:10.1017/S1366728916000675

Cunnings, I. (2017b). Interference in Native and NonNative Sentence Processing. Bilingualism: Language and Cognition, 20. doi:10.1017/S1366728916001243

Dillon, B. (2017). A short discourse on reflexives: A reply to Cunnings (2016). Bilingualism: Language and Cognition, 20. doi:10.1017/S1366728916000973

Dussias, P., Beatty-Martínez, A., \& Perrotti, L. (2017). Susceptibility to interference affects the second and the first language. Bilingualism: Language and Cognition, 20. doi:10.1017/S1366728916001024

Ferreira, F., \& Patson, N. D. (2007). The 'good enough' approach to language comprehension. Language and Linguistics Compass, 1, 71-83. doi:10.1111/j.1749818X.2007.00007.x

Futrell, R., \& Gibson, E. (2017). L2 processing as noisy channel language comprehension. Bilingualism: Language and Cognition, 20. doi:10.1017/S1366728916001061

Gabriele, A., Fiorentino, R., \& Covey, L. (2017). Understanding the symptoms and sources of variability in second language sentence processing. Bilingualism: Language and Cognition, 20. doi:10.1017/S1366728916000961
Hamrick, P., \& Ullman, M. (2017). A neurocognitive perspective on retrieval interference in L2 sentence processing. Bilingualism: Language and Cognition, 20. doi:10.1017/S136672891600081X

Hopp, H. (2016). Learning (not) to predict: Grammatical gender processing in second language acquisition. Second Language Research, 32, 277-307. doi: $10.1177 / 0267658315624960$

Hopp, H. (2017). Individual differences in L2 parsing and lexical representations. Bilingualism: Language and Cognition, 20. doi:10.1017/S1366728916000821

Jacob, G., Lago, S., \& Patterson, C. (2017). L2 processing and memory retrieval: Some empirical and conceptual challenges. Bilingualism: Language and Cognition, 20. doi:10.1017/s1366728916000948

Juffs, A. (2017). Construct operationalization, L1 effects, and context in second language processing. Bilingualism: Language and Cognition, 20. doi:10.1017/S1366728916000900

Kaan, E. (2014). Predictive sentence processing in L2 and L1: What is different? Linguistic Approaches to Bilingualism, 4, 257-282. doi:10.1075/lab.4.2.05kaa

Kaan, E. (2017). Susceptibility to interference: Underlying mechanisms, and implications for prediction. Bilingualism: Language and Cognition, 20. doi:10.1017/S1366728916000894

Kaiser, E. (2017). On the role of discourse-level information in second-language sentence processing. Bilingualism: Language and Cognition, 20. doi:10.1017/S1366728916001012

Keating, G. (2017). L2 proficiency matters in comparative L1/L2 processing research. Bilingualism: Language and Cognition, 20. doi:10.1017/S1366728916000912

Lewis, R. L., Vasishth, S., \& Van Dyke, J. A. (2006). Computational principles of working memory in sentence comprehension. Trends in Cognitive Sciences, 10, 447-454. doi:10.1016/j.tics.2006.08.007

Malko, A., Ehrenhofer, L., \& Phillips, C. (2017). Theories and frameworks in second language processing. Bilingualism: Language and Cognition, 20. doi:10.1017/s1366728916001000

McDonald, J. L. (2006). Beyond the critical period: Processing-based explanations for poor grammaticality judgment performance by late second language learners. Journal of Memory and Language, 55, 381-401. doi:10.1016/j.jml.2006.06.006

Montrul, S., \& Tanner, D. (2017). Individual differences and retrieval interference in L2 processing. Bilingualism: Language and Cognition, 20. doi:10.1017/S136672891600095X

Omaki, A. (2017). Linking learning and parsing in bilingual sentence processing. Bilingualism: Language and Cognition, 20. doi:10.1017/ S1366728916000985

Tremblay, A., \& Coughlin, C. E. (2017). Cue-Weighting mechanism and bilingualism. Bilingualism: Language and Cognition, 20. doi: 10.1017/s1366728916001036

Wagers, M. (2017). Sources of variability in linguistic memory systems. Bilingualism: Language and Cognition, 20. doi:10.1017/S1366728916000997 